\title{
CORPORATE ETHICAL ORIENTATION: IMPACT ON ETHICAL BEHAVIOUR AND PERSON JOB FIT
}

\author{
Aswathy Mohan \\ Bhavan's Royal Institute of Management, Tripunithura, Ernakulam-Kerala. \\ Dr S. Chandramohan \\ Alagappa Institute of Management, Alagappa University, Karaikudi-Tamil Nadu.
}

\begin{abstract}
The presence of regulations and code of ethics is not a panacea for ensuring ethical conduct of business. In practice we notice that corporate giants comply with all the regulations put forth by the law but are not able to sustain in their businesses. Understanding the need for being ethical in a sector like micro finance and learning the challenges of the sector. This study tries to analyze how employees perceive about the ethical context of their organization and how it relates to the ethical behavior of the employees and analyses whether it impacts the person job fit. The study uses MANOVA, correlation and regression to tests the hypotheses. It was evident from the descriptive that respondents perceived their organisations as ethical and exhibited an ethical behaviour and they perceived a moderate fit with their job roles. The findings showed that the perception about ethical orientation of the organisation, ethical behavior and person job fit shows a significant relation to the departments they belong to, tenure in the present organisation and the experience in the sector. The significant relationship between the variables reveal that if the organisations can nurture an ethical orientation amongst its employees would contribute to positive outcomes like ethical behavior and person job fit which are related many other positive performance measures. The regression results showed that the corporate ethical orientation creates an impact on the ethical behavior and person job fit.
\end{abstract}

Key words: Corporate Ethical Orientation, Ethical Behaviours, Person Job Fit, Microfinance Sector.

Cite this Article: Aswathy Mohan and S. Chandramohan, Corporate Ethical Orientation: Impact on Ethical Behaviour and Person Job Fit, International Journal of Management, 11(12), 2020, pp. 1-11.

http://iaeme.com/Home/issue/IJM?Volume=11\&Issue=12 


\section{INTRODUCTION}

Over the years we have noticed a drastic increase in the number of unethical actions in business globally (eg: Enron, Worldcom). The presence of regulations and code of ethics is not a panacea for ensuring ethical conduct of business. In practice we notice that corporate giants comply with all the regulations put forth by the law but are not able to sustain in their businesses. The best example from India is the collapse of Satyam which was even the recipient of Golden Peacock Award for Corporate Governance in 2008.

This has gained the attention of both researchers and practitioners. Even though it has paved way to more stringent Corporate Governance regulations in India. Recent bank scandals and others have shaken the regulators and questioned the very existence of such regulations. Thus, it can be inferred that ensuring effective governance is much more than complying with the recommendations put forth by several committees. This has made the researchers to think on the need for assessing the ethical orientation of the organization and its stakeholders. This make it more evident that a corporate's ethical values and the presence of an ethical environment is inevitable in deciding the ethical behaviour of the employees.

Thus, came the thought of corporate governance as an organizational issue which necessitate the presence of an ethical environment and the need to assess an employees' perception of organization's ethical orientation. But the pace at which the business environment changes globally makes it difficult to prioritize on the ethical orientation of the corporates. Currently, it is highly essential to make ethics and value as a standard tactic for all. The dynamic environment of the business and the technological changes are creating new consideration for ethical theories in the organisation. The need for being ethical gains more importance in the financial services industry as it contributes to support the economic activities of the people. Moreover, poverty alleviation is one among the important objectives of the government and sectors like micro-finance is playing a vital role for the aforesaid objective. MFIs are institutions with a dual objective of providing financial services to lower income group and also achieve a minimum rate of growth. This mission drift of commercial profitability and social impact in Micro Finance Institutions(MFIs) makes the need for being ethical more vital. India being a hub of MFIs, the high interest rates charged by MFIs to maintain their operational efficiency has led critics to think that they are not being true to their social function and ethical content. Also, their desire for rapid growth has resulted in increased number of operational frauds. The interactions with the experts from the industry revealed that as a result of the strong decentralised model of MFIs make them more vulnerable to frauds. Some of the areas that make these MFIs vulnerable to frauds are constant changes happening in the system, turnover rate amongst the sales staff, handling of excessive cash, intense competition etc. After understanding the need for being ethical in a sector like micro finance and learning the challenges of the sector. This study tries to analyze how employees perceive about the ethical context of their organization and how it relates to the ethical behavior of the employees and analyses whether it impacts the person job fit.

\section{RELATED LITERATURE}

\subsection{Corporate Ethical Orientation}

Business Ethics was an area of interest even before the 1980's. Most of the companies resorted to drafting of codes and compliance of which was expected to make an ethical organization. But this did not prove to be a panacea for improving the ethical orientation of companies. In the present scenario companies have realized that a culture which brings an ethical orientation to its employees is highly essential apart from having a code of ethics. (Stevens, Vol. 20, No. 2 (Jun., 1999)). Codes become successful when the employees can 
understand what to do and what not to. Moreover, it should become a part of the corporate culture than imposing it on the staff who find it difficult to accept the corporate values. (Sean Valentine, 2004). Organizations play an important role in determining the behavior of employees (Mischel, 1968). "Organizational culture influences thoughts and feelings and guides behavior," and "manifests itself in norms, rituals, ceremonies, legends, and the organizational choice of heroes and heroines" (Trevino, 1986). "Merely having standards is not enough, a company must make the standards understood, and ensure their proper dissemination within the organizational structure' (Palmer and Zakhem, 2001, p. 83) (Vasquez-Parraga, 1993) remarks on the role played by ethical culture in facilitating ethical behavior within the organisation. Corporate culture impacts the performance of the organization at an organizational level and impacts the behavioral intention at an individual level determining how employees make decisions in the organization. Corporate ethical value (CEV) is an important dimension of the organizational culture (Schein, 1984) that is likely to impact the behavior of the employees of an organization. However, this relationship between CEV and employee behaviors may not be always direct and may be influenced by other organizational and individual factors. $\mathrm{CEV}$ is considered as a subset of organisation culture which consists of the various formal and informal systems of controlling the behaviors of the individual within the organization (Trevino, 1998). The formal systems include the various policies and codes whereas the informal systems consist of the beliefs, norms and practices by the people in an organization (Key, 1999). The ethical orientations of the employees are exhibited through various behavioral norms and values. Majority of them stems from the top management's beliefs and get embedded within the structure of the organization. (Thomas L Baker, 2006). A higher CEV exist when the employees believe that policies and procedures regarding the ethics are followed by their peers. Moreover, the actions of the superiors in relation to ethical and unethical behaviors of the employees also tends to exhibit the CEV. (Trevino, 1986) "corporate ethical values" scale developed by (Hunt, 1989) and this instrument measures the "composite of the individual ethical values of managers and both the formal and informal policies on ethics of the organization' . Previous work suggests that this scale can be used effectively to evaluate ethical components of company culture (Barnett, 2002) and this study uses CEV scale to measure the employee perception of corporate ethical orientation.

\subsection{Ethical Behavior}

Previous researchers have studied the role of number of influences on ethical behavior. (Dubinsky, 1984) (Hunt V.-P. , 1993) (Schwepker, 2001) (Schwepker F. , 1997). Many of these influences may be grouped as individual or situational factors which includes stages of cognitive development, locus of control, demographic factors, ethical culture, rules, reward systems etc. (Singhapakdi, 1996) (Trevino Y., 1990) (Ford, 1994). Past literatures show little consistency with regard to what constitutes ethical behavior. (Navran, 1992) defines ethical behavior of individuals as one who is acting according to his own values. (Fraedrich, 1993) and (Hunt, 1990) recommends a constructionist approach which explains ethical behavior as the one prescribed by the respective organizations. As per this approach the acts of right and wrong is determined by the organizational norms and any deviance is unethical. (Brass, 1998) (Zey-Ferrell M, 1982) believed in a differential association theory under which ethical or unethical behaviors are determined by their associations with others or their presence in various social networks. This body of research related to ethical behavior yielded inconsistent results. It was found that more consistent results were determined through situational influences. (Ferrell, 1985). Hence it was identified as a researchable area to bring in more understanding to the factors that lead to ethical behavior of employees. The extent to which the employees connect themselves to the organization is expected to lead to ethical behavior. 
The measure was taken from (Fraedrich, 1993) for ethical behavior which was originally developed by (Ferrell S. , 1988) which measures the deviance from organizational norms.

\subsection{Person Job Fit}

It refers to the compatibility between employee attributes and their work environment. Earlier researchers have found that PJ fit increases the antecedents of work performance. (KristofBrown, 2005) like increasing the productivity and efficiency. The works that are characterized by challenging tasks, autonomy, and significance are important for employees who have high person-job fit. When work is in line with the employee's self-identity, then the work becomes more meaningful so that employees initiate innovative ideas and implement them in their work (Afsar, 2016) .Many studies have determined the positive consequences of PJ fit at individual and at organisation level like improving OCB, job satisfaction along with making the organisation's vision and mission successful. (Hamid, 2011)

(Chen C. Y., 2014) found that the congruence between the person and job attributes are likely to enhance the involvement that the employees exhibit in their roles. Person-Job Fit (PJ fit). PJ fit measurement uses 4 indicators adapted from (Cable, 2002) (e.g. "My abilities fit the demands of this job"). This study tries to study the PJ Fit among the employees at different levels of experience.

\section{METHODOLOGY}

\subsection{Research Goal}

Based on the review of literature done, this study was designed to learn how employees perceive their ethical orientation of their organisation and determine its impact on the individual factors like the ethical behaviour of employees and person job fit. Earlier studies have analysed the associations among $\mathrm{CEV}$, organisational commitment and person organisation fit (Valentine 2002) and indicated the impact of ethical environment on the behaviour of employees. (Chonko \& Hunt 1985,Hunt et.al 1984, Ford and Richardson 1994). The figure 1 given below depicts the conceptual model explored in the study. The other objectives of the study indicate how the variables of Corporate ethical value, ethical behaviour and person job fit differs according to the various demographic variables.

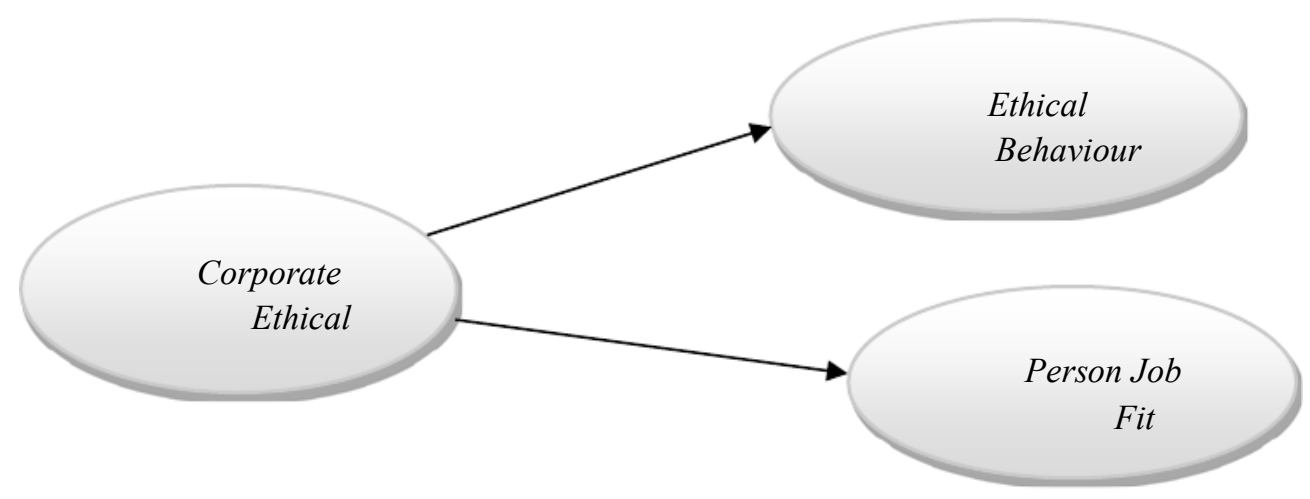

Figure 1: Conceptual Model

Source: - Data Analysis

\subsection{Development of hypotheses}

With reference to the literature reviewed and the interests of the study the following hypothesis were developed. 
H1: Corporate ethical orientation, ethical behavior and person job fit show differences according to independent groups based on their age, education, departments, tenure in the organization and the experience in the sector.

$\mathrm{H} 2$ : Corporate ethical orientation of companies influences the ethical behavior of employees.

H3: Corporate ethical orientation of companies relates to person-job fit.

\subsection{Sample and Data Collection}

The sampling frame for the study consisted of the KASAFI members which is an association of MFIs operating in Kerala. The population of the study consisted of employees who have completed a minimum of 3 years in microfinance sector. The study employed a simple random sampling method to choose the firms and collected data from 104 employees of these randomly selected firms who fulfils the criterion of minimum 3 years' experience in the MFI sector. The survey was conducted through questionnaires which was prepared with the scales used in earlier researches which measured the variables in the study. For the purpose of this study all variables were marked on a five-point Likert scale with anchors strongly disagree $(=1)$ to strongly agree $(=5)$. The various scales adopted are "corporate ethical values" scale developed by (Hunt, 1989) and this instrument measures the "composite of the individual ethical values of managers and both the formal and informal policies on ethics of the organization'". The measure was taken from (Fraedrich, 1993) for ethical behavior which was originally developed by (Ferrell S. , 1988) which measures the deviance from organizational norms. PJ fit measurement uses 4 indicators adapted from (Cable, 2002) (e.g. "My abilities fit the demands of this job"). Cronbach's alpha was used to examine the internal consistency (reliability) of the scale measurement items used for the study.

Table I: Reliability Statistics

\begin{tabular}{|l|l|}
\hline \multicolumn{1}{|c|}{ Scale } & \multicolumn{1}{|c|}{$\begin{array}{c}\text { Cronbach's } \\
\text { Alpha }\end{array}$} \\
\hline Corporate Ethical Value & 0.824 \\
\hline Ethical behaviour & 0.615 \\
\hline Person Job Fit & 0.802 \\
\hline
\end{tabular}

Source: - Data Analysis

The results of the Cronbach's alpha presented in Table I suggest that all measures in this study, ranged from 0.615 to 0.824 , are reliable as recommended by Hair et al. (2003), and well above the required threshold of 0.6 (Goffee, 1996). The scales which had negative items were reverse scored, values were averaged in a range of 1 to 5 where higher scores indicated greater ethical orientation in the firms, ethical behavior and person job fit. The descriptive statistics of the variables under study were initially determined. The bivariate relationships among the variables were found out by correlation analysis. MANOVA and Regression Analysis was used to test the study's hypotheses using SPSS.

\section{RESULTS}

\subsection{Sample Characteristics}

A summary of the characteristics of the sample chosen for the study is presented in the Table II. It reveals that more than half of the sample consists of married male employees. Majority 
of the employees fall in the age group of 36-40 Years (46.2\%) followed by age group of 3135 years $(30.8 \%)$. It is also found that majority falls in the category of graduate or postgraduate. It was also found that a majority falls into the Operations department $(69.2 \%)$ followed by Finance \& Accounts (15.4\%), Human resource $(7.7 \%)$ and rest falls into the others category. When the tenure of experience is considered in the present organisation majority falls into the category of 2.5 years. Due to the need to understand ethical orientation of the MFI sector sample consisted of employees with a minimum experience of 3 years and was found that majority fall to the 5-10 years category $(53.8 \%)$ followed by more than 10 years $(38.5 \%)$.

Table II: Sample Characteristics

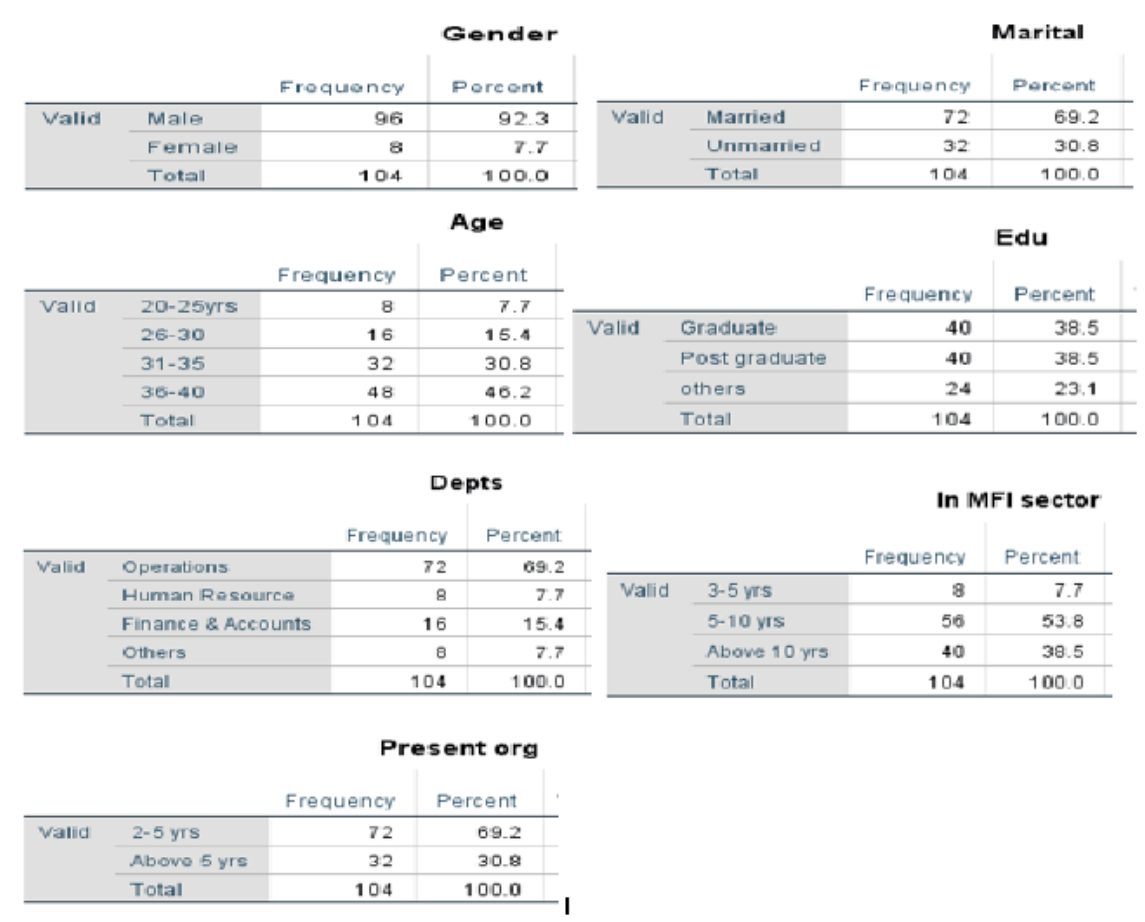

Source: - Data Analysis

\subsection{Item Descriptive Statistics}

The item descriptive statistics are presented in Table III. Mean Scores for the variables indicated that respondents perceived their organisations as ethical and exhibited an ethical behaviour and they perceived a moderate fit with their job roles.

Table III: Descriptive Statistics

\begin{tabular}{|l|c|c|c|c|c|}
\hline \multicolumn{7}{|c|}{ Descriptive Statistics } \\
\hline & N & Minimum & Maximum & Mean & Std. Deviation \\
\hline CEV & 104 & 3.40 & 5.00 & 4.6615 & .51319 \\
\hline EB & 104 & 2.70 & 4.60 & 3.8385 & .53541 \\
\hline PJF & 104 & 3.22 & 5.00 & 4.4872 & .50984 \\
\hline Valid N (listwise) & 104 & & & & \\
\hline
\end{tabular}

Source: Data Analysis 


\subsection{Multivariate Analysis of Variance ( MANOVA)}

The one-way MANOVA was used to determine whether there are any difference between independent groups based on age, education, departments, years of experience in the present organisation and the experience in the MFI sector. The results of MANOVA as presented in the Table IV reveals that all the independent groups show significant difference in the variables like ethical orientation of the company, ethical behavior of employees and person job fit. Further when explored in the tests of between subject effects it was found that the person job fit does not show a significant difference between age groups and the ethical behavior exhibited by the employees also show no difference based on the level of education. The findings of MANOVA showed that the perception about ethical orientation of the organisation, ethical behavior and person job fit shows a significant relation to the departments they belong to, tenure in the present organisation and the experience in the sector.

Table IV: Multivariate tests

\begin{tabular}{|l|c|c|c|}
\hline \multicolumn{1}{|c|}{ Effect } & Wilks' Lambda & F & p-value \\
\hline Age & 0.631 & 5.515 & 0.00 \\
\hline Education & 0.395 & 19.526 & 0.00 \\
\hline Departments & 0.029 & 87.662 & 0.00 \\
\hline Tenure & 0.624 & 20.074 & 0.00 \\
\hline Total experience & 0.179 & 45.077 & 0.00 \\
\hline
\end{tabular}

Source: - Data Analysis

\subsection{Correlation matrix}

The results of the correlation analysis of the variables are presented in Table V. The analysis of the bivariate relationships showed that the items used to measure ethical orientation of companies were positively relate to ethical behavior and person job fit. The items of ethical behavior were also positively related to the items of person job fit. This significant relationship between the variables reveal that if the organisations can nurture an ethical orientation amongst its employees would contribute to positive outcomes like ethical behavior and person job fit which are related many other positive performance measures as studied in the past literatures. (Valentine and Barnett, 2002)

Table V: Correlation Matrix

\begin{tabular}{|c|c|c|c|c|}
\hline \multicolumn{5}{|c|}{ Correlations } \\
\hline & & PJF & EB & CEV \\
\hline \multirow[t]{3}{*}{ P.JF } & Pearson Correlation & 1 & $857^{x \pi}$ & $669^{x \times}$ \\
\hline & Sig. (2-tailed) & & .000 & .000 \\
\hline & $N$ & 104 & 104 & 104 \\
\hline \multirow[t]{3}{*}{ EB } & Pearson Correlation & $.857^{\mathrm{nx}}$ & 1 & $.698^{* n}$ \\
\hline & Sig. (2-tailed) & .000 & & .000 \\
\hline & $N$ & 104 & 104 & 104 \\
\hline \multirow[t]{3}{*}{ CEV } & Pearson Correlation & $.669^{n \times x}$ & $.698^{* \pi}$ & 1 \\
\hline & Sig. (2-tailed) & .000 & .000 & \\
\hline & $N$ & 104 & 104 & 104 \\
\hline
\end{tabular}

Source: - Data Analysis 


\subsection{Regression Analysis}

The univariate regression analysis was used to test the hypotheses which does not allow collinearity of the variables to confound the findings. The Table VI and VII presents the regression results.

Table VI: Regression Analysis 1

\begin{tabular}{|c|c|c|c|c|c|c|}
\hline \multicolumn{7}{|c|}{ Coefficients $^{a}$} \\
\hline \multirow[b]{2}{*}{ Model } & & \multicolumn{2}{|c|}{ Unstandardized Coefficients } & \multirow{2}{*}{$\begin{array}{c}\text { Standardized } \\
\text { Coefficients } \\
\text { Beta }\end{array}$} & \multirow[b]{2}{*}{$\mathrm{t}$} & \multirow[b]{2}{*}{ Sig. } \\
\hline & & B & Std. Error & & & \\
\hline \multirow[t]{2}{*}{1} & (Constant) & 4.438 & 3.469 & & 1.279 & .204 \\
\hline & CEV & 1.456 & .148 & .698 & 9.844 & .000 \\
\hline
\end{tabular}

Source: - Data Analysis

Table VI provides the details about the positive impact of corporate ethical orientation on the ethical behavior of employees. The findings support the hypothesis set which explains the influence of corporate ethical value on the ethical behavior of employees. The $\mathrm{R}$ square value comes to 0.487 which reveals that $48.7 \%$ of the variance in ethical behavior of employees is explained by the predictor variable which adds strength to the model. This result is in congruence with the results of the previous researchers ((McDonald, 1999)

Table VII: Regression Analysis 2

\begin{tabular}{|c|c|c|c|c|c|c|}
\hline \multicolumn{7}{|c|}{ Coefficients $^{a}$} \\
\hline & & \multicolumn{2}{|c|}{ Unstandardized Coefficients } & \multirow{2}{*}{$\begin{array}{l}\text { Standardized } \\
\text { Coefficients } \\
\text { Beta }\end{array}$} & \multirow[b]{2}{*}{$t$} & \multirow[b]{2}{*}{ Sig. } \\
\hline Model & & $\mathrm{B}$ & Std. Error & & & \\
\hline \multirow[t]{2}{*}{1} & (Constant) & 12.487 & 3.085 & & 4.048 & .000 \\
\hline & CEV & 1.197 & .132 & .669 & 9.098 & .000 \\
\hline
\end{tabular}

Source: - Data Analysis

The second model of regression also supports the hypothesis that the corporate ethical orientation is likely to positively influence the person job fit. The $\mathrm{R}$ square of 0.448 explain the high degree of strength of the model and $p<0.001$ proves the statistical significance. Thus, proves that corporate ethical values are likely to influence the person job fit which adds to the previous research (Valentine 2002) which explains the structural relationship between ethical context and person organisation fit.

The results of the analysis provide statistical support for the hypothesis set in the study. The next section provides the managerial implications of the results, limitations of the study and recommendations for future research.

\section{DISCUSSION AND MANAGERIAL IMPLICATIONS}

Most of the researches have indicated that the businesses should try to enhance the ethical context as "good ethics is good business". The findings of this study also supplement this widely held conclusion. This becomes more vital in sectors like microfinance as the customers identify employees with the organisation and often regard employees as brand ambassadors of the institutions operating in the sctor. The initial part of the analysis reveals 
that tenure an employee spends in an organisation plays an important role in perceiving the ethical orientation of the firm. Similar findings were obtained for the experience in the industry and departments to which the employees belong. Hence it becomes essential that to improve the corporate ethical orientation the firms have to reduce attrition rate and make use of strategies that encourage the employees to continue in their present organisation. Thus, more years that one spends in an organisation contributes to better perception about companies ethical context and also the employees belonging to finance and operations department are more likely to have an ethical orientation than the other departments. This finding may be compared with previous researchers' finding that perceptions of organizational ethics are commonly built by drafting an ethics code (Adams et al., 2001; Valentine and Barnett, 2002), which is out of the purview of this study. Several managerial implications stem from these results. As a primary corporate strategy, companies can offer ethics training that include key company values and top leadership should ideally oversee such training so that its importance is emphasized in the organization (Ferrell and Gresham, 1985; Fritz et al., 1999; James, 2000; Viswesvaran et al., 1998; Vitell and Davis, 1990). Top management should employ more efforts to emphasise the importance of employee behavior while managing the organisational ethical environment.

The results of the correlation and regression analysis reveals that an organisational factor like corporate ethical orientation was found to bring about impact on individual factors like ethical behavior of employees and person job fit. It is a vital finding that if companies can bring about an ethical context in their activities and undertakes steps to make the employees aware about the ethical principles the companies uphold it contributes several positive consequences. Similarly, Jaramillo et al. (2006) conclude that higher job satisfaction leads to greater commitment, which in turn leads to greater levels in performance. Thus, a firm that has an enhanced level of ethical perceptions should logically find that these perceptions lead to greater performance. Obviously, higher performance levels translate into greater profits for the firm. The study's results imply that organizational ethical principles are associated with more positive work attitudes. Programs that institutionalize these values like ethics codes and training should therefore be implemented along with other enrichment-based initiatives that increase employees' work perceptions, motivation, and attachment to a company (Parker and Wall, 1998). By "increasing the relevance of the frameworks and models of business ethics to the daily lives of managers and other business stakeholders" (Werhane and Freeman, 1999), overall company performance will likely be increased.

\section{LIMITATIONS AND FUTURE RESEARCH}

Some of the limitations of the study are that it did not try to investigate sources from which the employees learned about ethics and other company related factors. Another major limitation is that study included only the employees from the micro finance sector hence the the generalizability of the result is limited. The use of subjective self-report information may have affected the accurate measurement of the study variables.

Future research can address what are the other work phenomena which are related to an ethical context. Secondly, replicating this study with samples from other sectors. Exploring how the impact of ethical training programme on employees differs according to their departments. Moreover, the effectiveness of various ways of providing training like lectures, role plays, games or simulation could be determined.

Even though ethics can be taught in the workplace is the subject of frequent debate (Cragg, 1997). Some believe we learn ethics and values as children from family and religious training rather than on the job (Stevens, 1997). By "increasing the relevance of the frameworks and models of business ethics to the daily lives of managers and other business 
stakeholders" (Werhane and Freeman, 1999), overall company performance will likely be increased. Overall this study supports the notion that a company to develop a good corporate image wants to become a part of societal principles and norms (Hartman 1996) and there is an increasing demand from the public to improve corporate ethics and the managers play a key role in developing the ethical orientation.

\section{REFERENCES}

[1] Afsar, B. B. (2016). The mediating role of psychological empowerment on the relationship between person-organization fit and innovative work behaviour. . Journal of Chinese Human Resource Management, 5-26.

[2] Barnett, S. V. (2002). Ethics Codes and Sales Professionals' Perceptions of Their Organizations' Ethical Values . Journal of Business Ethics, 191-200.

[3] Brass, B. (1998). Relationships and unethical behavior a social network perspective. AMReview, 14-31.

[4] Cable, D. D. (2002). Journal of Applied Psychology, 875-884.

[5] Cable, D. D. (2002). The convergent and discriminant validity of subjective fit perceptions. . Journal of Applied Psychology, 875-884.

[6] Chen, A. R. (1997). 'Reinforcing Ethical Decision Making Through Corporate Culture. Journal of Business ethics, 855-865.

[7] Chen, C. Y. (2014). Job crafting and job engagement: The mediating role of person-job fit. International Journal of hospitality management, 21-28.

[8] Compion, M. A. (1991). Meaning and measurement of turnover comparison of alternative measures and recommendations for research. Journal of Applied Psychology, 199-212.

[9] Dubinsky, I. (1984). Correlates of salespeople's ethical conflict: an exploratory investigation. JBE, 43-53.

[10] Ferrell, G. (1985). 'A Contingency Framework for Understanding Ethical Decision Making in Marketing',. Journal of Marketing, 87-96.

[11] Ferrell, S. (1988). 'Ethical Behavior and Bureaucratic Structure in Marketing Research Or ganizations', . Journal of Marketing Research, 103-109.

[12] Ford, R. (1994). Ethical decision making in marketing; A review of the empirical literature. Journal of Business Ethics, 205-221.

[13] Fraedrich. (1993). The ethical behavior of retail managers. journal of Business Ethics, 207218.

[14] Hamid, S. Y. (2011). 1-30.

[15] Hamid, S. Y. (2011). Relationship between person-job fit and personorganisation fit on employees' work engagement: a study among engineers in semiconductor companies in Malaysia. . Annual Conference on Innovations in Business \& Management, London, 1-30.

[16] Hang-Yue, N. F. (2005). Work role stressors and turnover intentions: a study of professional clergy in Hong Kong. . International Journal of Human Resource Management, 2133-2146.

[17] Hunt. (1990). 'Truth in Marketing Theory and Research', . Journal of Marketing , 1-15.

[18] Hunt, V.-P. (1993). Organisation consequences,marketing ethics and salesforce supervision. Journal of Marketing Research, 78-90.

[19] Hunt, W. (1989). Corporate ethical value and organisational committment in marketing. Journal of marketing, 79-90.

[20] Iiyas, S. (2013). Combined effects of person job fit and organization commitment on attitudinal outcomes such as job satisfaction and intention to quit. . WEI International Academic Conference Proceedings.

[21] Jose, A. a. (1993). 'Institutionalization of Ethics: The Perspective of Managers'. Journal of Business ethics, 133-143. 
[22] Key. (1999). Organisational Ethical culture: Real or Imagined? Journal of Business Ethics, 217-25.

[23] Kristof, A. L. (1996). 'Person-Organization Fit: An Integrative Review of Its Conceptualizations, Measurement, and Implications'. Personnel Psychology, 1-49.

[24] Kristof-Brown, A. Z. (2005). Personnel Psychology, 281-342.

[25] Kristof-Brown, A. Z. (2005). Consequences of individuals' fit at work: a meta-analysis of person-job, person-organization, person-group, and personsupervisor fit. Personnel Psychology, 281-342.

[26] Laufer, W. S. (1997). 'Corporate Ethics Initiatives as Social Control'. Journal of Business ethics, 1029-1048.

[27] Loi, R. H.-Y. (2006). Linking employee justice perceptions to organizational commitment and intention to leave: the mediating role of perceived organizational support. . Journal of Occupational and Organisational Psychology, 101-120.

[28] Navran. (1992). Your role in shaping ethics. Exec Excell, 11-13.

[29] Schein. (1984). Coming to a new awareness of organisational culture. Sloan mangement Review, 3-16.

[30] Schwepker. (2001). Ethical climate's relationship to job satisfaction,organisational committment and turnover intentions in salesforce. Journal of Business Research, 39-52.

[31] Schwepker, F. (1997). The influence of ethical climate and ethical conflict on role stress in the salesforce. Journal of Academic Marketing Science, 99-108.

[32] Sean Valentine, G. F. (2004). Ethics Training and Businesspersons' Perceptions of Organizational Ethics. Journal of Business Ethics, 381-390.

[33] Singhapakdi, V. (1996). Moral Intensity and ethical decision making of marketing professions. Journal of business Research, 245-255.

[34] Stevens, B. (Vol. 20, No. 2 (Jun., 1999)). Communicating Ethical Values: A Study of Employee Perceptions . Journal of Business Ethics, 113-120.

[35] Thomas L Baker, T. G. (2006). Promoting Ethical behavior and organizational citizenship behaviors: The influence of Corporate ethical values. Journal of Business Research , 849-857.

[36] Trevino. (1986). Ethical decision Making in organisation: a person, situation interactionist model. Academy of Management Review, 601-17.

[37] Trevino. (1998). The ethical context in organisation influences on employee attitudes and behaviors. business Ethics Q, 447-76.

[38] Trevino, Y. (1990). Bad apples in bad barrels:a causal analysis of ethical decision making behavior. Journal of Applied psychology, 378-385.

[39] Valentine, S. (2002). Ethical Context, Organizational Commitment, and Person-Organization Fit. Journal of Business ethics, 349-360.

[40] Van Breukelen, W. v. (2004). Voluntary employee turnover: combining variables from the traditional to literature with the theory of planned behaviour. . Journal of Organizational Behaviour, , 893-914.

[41] Vasquez-Parraga, H. \&. (1993). Organisational consequences, marketing ethics and salesforce supervision. Journal of marketing Research, 78-90.

[42] Vidaver-Cohen, D. (1998). 'Moral Climate in Business Firms: A Conceptual Framework for Analysis and Change,'. Journal of Business Ethics, 1211-1226.

[43] Zey-Ferrell M, F. O. (1982). Role-set configuration and opportunity as predictors of unethical behavior in organisation. Human Relations, 587-604. 